\title{
Managing the pools of cellular redox buffers and the control of oxidative stress during the ontogeny of drought-exposed mungbean (Vigna radiata L.) - role of sulfur nutrition
}

\author{
Naser A. Anjum ${ }^{1,2}$, Shahid Umar ${ }^{1}$, Ibrahim M. Aref ${ }^{3}$ and Muhammad Iqbal ${ }^{1 *}$ \\ ${ }^{1}$ Department of Botany, Faculty of Science, Hamdard University, New Delhi, India \\ 2 Department of Chemistry, CESAM-Centre for Environmental and Marine Studies, University of Aveiro, Aveiro, Portugal \\ ${ }^{3}$ Plant Production Department, College of Food and Agricultural Sciences, King Saud University, Riyadh, Saudi Arabia
}

Edited by:

Adriano Sofo, Università degli Studi della Basilicata, Italy

\section{Reviewed by:}

Yogesh Abrol, Bhagalpur University, India

Kumar Ajit, University of South

Australia, Australia

*Correspondence:

Muhammad lqbal, Department of

Botany, Faculty of Science,

Hamdard University, New Delhi,

110062, India

e-mail: iqbalg5@yahoo.co.in
Impacts of increasing environmental stresses (such as drought) on crop productivity can be sustainably minimized by using plant-beneficial mineral nutrients (such as sulfur, S). This study, based on a pot-culture experiment conducted in greenhouse condition, investigates S-mediated influence of drought stress (imposed at pre-flowering, flowering, and pod-filling stages) on growth, photosynthesis and tolerance of mungbean (Vigna radiata L.) plants. Drought stress alone hampered photosynthesis functions, enhanced oxidative stress [measured in terms of $\mathrm{H}_{2} \mathrm{O}_{2}$; lipid peroxidation (LPO); electrolyte leakage (EL)] and decreased the pools of cellular redox buffers (namely ascorbate (AsA); glutathione (GSH)], and the overall plant growth (measured as leaf area and plant dry mass), maximally at flowering stage, followed by pre-flowering and pod-filling stages. Contrarily, S-supplementation to drought-affected plants (particularly at flowering stage) improved the growth- and photosynthesis-related parameters considerably. This may be ascribed to S-induced enhancements in the pools of reduced AsA and GSH, which jointly manage the balance between the production and scavenging of $\mathrm{H}_{2} \mathrm{O}_{2}$ and stabilize cell membrane by decreasing LPO and EL. It is inferred that alleviation of drought-caused oxidative stress depends largely on the status of AsA and GSH via S-supplementation to drought-stressed $V$. radiata at an appropriate stage of plant growth, when this nutrient is maximally or efficiently utilized.

Keywords: cellular buffers, drought stress, mungbean ontogeny, oxidative stress, sulfur, Vigna radiata

\section{INTRODUCTION}

Recognized as one of the major environmental stress factors, and as a main constraint for crop production worldwide, drought affects virtually every aspect of plant growth, physiology and metabolism (Harb et al., 2010). In particular, at the wholeplant level, drought stress affects mainly the plant photosynthetic functions, causing imbalance in " $\mathrm{CO}_{2}$ fixation and electron transport." This facilitates transfer of electrons to reactive oxygen species (ROS), including $\mathrm{H}_{2} \mathrm{O}_{2}$, as a result of over-reduction of the electron-transport-chain components (Anjum et al., 2008a; Lawlor and Tezara, 2009). Additionally, high concentration of ROS causes oxidative damage to photosynthetic pigments, biomolecules such as lipids, proteins and nucleic acids, and leakage of electrolytes via lipid peroxidation (LPO), leading to cessation of normal plant cellular metabolism (Anjum et al., 2012a). The ascorbate-glutathione (AsA-GSH) pathway constitutes the major part of antioxidant defense system in plants where a number of ROS are effectively metabolized and/or detoxified by a network of reactions involving enzymes and metabolites with redox properties. Both AsA and GSH (tripeptide GSH; $\gamma$-glutamate-cysteine-glycine) are cellular redox buffers closely linked in major physiological functions. Nevertheless, in conjunction with other components of AsA-GSH pathway, both AsA and GSH together determine the lifetime of varied ROS and their reaction products within the cellular environment and provide crucial protection against oxidative damage (Anjum et al., 2010, 2012a, 2013). In recent studies, exogenous application of AsA or GSH was reported to help plants to withstand consequences caused by a range of abiotic stresses including Cd (Cai et al., 2011; Son et al., 2014), salinity (Wang et al., 2014) and high temperature (Nahar et al., 2015).

Maintenance of the status of mineral nutrients in plants is important for increasing the crop productivity and plant resistance to environmental stress (Cakmak, 2005; Anjum et al., 2008b, 2012b). The cumulative role of mineral nutrients in modulating cellular levels of AsA and GSH, and in strengthening the plant antioxidant defense system has been discussed extensively (Anjum et al., 2010, 2012a, 2013; Gill et al., 2011). Sulfur (S) is the fourth essential macronutrient for plants, after N, P and $\mathrm{K}$, and plays a vital role in the regulation of plant growth, 
development and productivity (Hawkesford, 2000), via affecting leaf chlorophyll, $\mathrm{N}$ content and photosynthetic enzymes. Sulfur is required for protein synthesis, incorporated into organic molecules in plants, and is located in thiol $(-\mathrm{SH})$ groups in proteins (cysteine-residues) or non-protein thiols (glutathione, GSH), the potential modulators of stress response (Anjum et al., 2008b; Lunde et al., 2008). Significance of plant ontogeny in the modulation of plant responses to abiotic stress factors such as drought (Anjum et al., 2008a) and heavy metals (Anjum et al., 2008c) has been reported. Also, considering a single plant growth-stage, the role of $S$ nutrition in the improvement of plant growth, development and yield (Ahmad et al., 2005), and tolerance to stresses (such as Cd; Anjum et al., 2008b) has been evidenced. However, information is meager on the Smediated control of plant responses to drought stress during plant ontogeny.

Given the paucity of information on drought sensitivity of legume crops, and on the physiological basis of mineralnutrient-(like S)-assisted management of crop growth and productivity, the current study was undertaken (i) to screen the drought-sensitive stage(s) during plant ontogeny, (ii) to identify the plant-growth stage when $\mathrm{S}$ helps plants maximally to improve the pools of both cellular redox buffers (AsA, GSH) and mineral-nutrients $(\mathrm{K}, \mathrm{S}$, and $\mathrm{Mg}$ ) in order to counteract the drought-accrued oxidative stress (measured as electrolyte leakage (EL), membrane lipid peroxidation and $\mathrm{H}_{2} \mathrm{O}_{2}$ levels). Mungbean (Vigna radiata L. Wilczek) was chosen as a model plant system for the current study, because it is a potential pulse crop in the Indian sub-continent due to its ready market, $\mathrm{N}_{2}$-fixation capability, early maturity and the ability to fit well in croprotation program (Anjum, 2006). Additionally, S-requirement of the pulse crops, for maintaining their normal growth and development, stands just second to that of the oil-yielding crops.

\section{MATERIALS AND METHODS EXPERIMENTAL MATERIALS, PROCEDURE AND SOIL CHARACTERISTICS}

Seeds of mungbean (Vigna radiata L. Wilczek) cultivar Pusa 9531 were sown in $30-\mathrm{cm}$-diameter earthen pots filled with $8 \mathrm{~kg}$ soil. The soil was sandy loam in texture, with $7.8 \mathrm{pH} 7.8,0.38 \mathrm{dsm}$ electrical conductivity, $0.43 \%$ organic carbon, $70 \mathrm{mg} \mathrm{kg}^{-1}$ soil available $\mathrm{K}$ and $5 \mathrm{mg} \mathrm{kg}^{-1}$ soil available S. Nitrogen $(\mathrm{N} ; 120 \mathrm{mg}$ $\mathrm{kg}^{-1}$ soil) and phosphorus ( $\mathrm{P} ; 30 \mathrm{mg} \mathrm{kg}^{-1}$ soil) were applied at the time of sowing. S was applied to $V$. radiata plants at the rate of $40 \mathrm{mg} \mathrm{kg}^{-1}$ soil, in the form of solution, 5 days before droughtstress imposition at various growth stages. The sources of $\mathrm{N}, \mathrm{P}$, $\mathrm{K}$, and $\mathrm{S}$ were urea, single super phosphate, gypsum, and muriate of potash, respectively. After germination, three plants per pot were maintained until harvest. The pots were kept in green house under semi-controlled condition. A polythene plastic film was used to thwart the effects of rainfall, which allowed transmittance of $90 \%$ of visible wavelength $(400-700 \mathrm{~nm})$ under natural day and night conditions with a day/night temperature 25/20 \pm $4^{\circ} \mathrm{C}$ and relative humidity of $70 \pm 5 \%$. All experiments were performed using completely expanded leaves from the second youngest nodes from the top of the plants.

\section{DROUGHT STRESS IMPOSITION AND SULFUR (S) APPLICATION SCHEDULE}

Drought was imposed at pre-flowering (15 d after sowing) (group 1), flowering ( $30 \mathrm{~d}$ after sowing) (group 2) and at pod filling (50 d after sowing) (group 3 ) by withholding water for 5 days; this was followed by normal watering (without S). Other three groups (4$6)$ as well as the controls were supplied with an equal amount of S solution ( $40 \mathrm{mg} \mathrm{S} \mathrm{kg}^{-1}$ ). All these (1-6) plant groups, and the control group, were maintained until harvest, and watered on alternate days. Soil moisture content was measured gravimetrically on dry weight basis at the time of pre-flowering, flowering, and post-flowering (pod-filling) stages (Table 1). Samplings were done after re-watering the drought-exposed plants for 5 days at the given growth stage i.e., at 25, 40, and 60 days after sowing. The treatments were arranged in a randomized complete block design, and each treatment was replicated five times.

\section{PLANT GROWTH, PHOTOSYNTHESIS AND BIOCHEMICAL ESTIMATIONS}

Leaf area was measured with a leaf area meter (LI-3000A, LICOR, Lincoln, NE). Plant dry mass was determined after drying the plant at $80^{\circ} \mathrm{C}$ to a constant weight with the help of an electronic balance (SD-300). Net photosynthetic rate $(\mathrm{P} n)$, stomatal conductance $(\mathrm{Gs})$ and intercellular $\mathrm{CO}_{2}$ concentration $(\mathrm{C} i)$ were recorded in fully expanded leaves of second youngest nodes, using infra-red gas analyzer (IRGA, LI-COR, 6400, Lincoln, NE) on a sunny day between 10:00 and 11:00 h. Chlorophyll content was estimated in fully expanded young leaves at each stage using the method given by Hiscox and Israelstam (1979). Estimation of soluble protein content was done according to Bradford (1976) using bovine serum albumin as standard.

\section{OXIDATIVE STRESS TRAITS}

We considered electrolyte leakage (EL), membrane lipid peroxidation and $\mathrm{H}_{2} \mathrm{O}_{2}$ levels as the biomarkers of oxidative stress. Cellular membrane integrity in leaves was assayed by measuring the EL according to Anjum et al. (2013). In brief, fresh leaves $(1.0 \mathrm{~g})$ were kept in glass vials containing $10 \mathrm{ml}$ deionized water.

Table 1 | Soil moisture content (\%) measured in the control and drought-stressed conditions [with and without sulfur (S) supply], at pre-flowering, flowering and pod-filling stages of mungbean (Vigna radiata) plants. Values are the means of five replicates \pm standard deviation.

\begin{tabular}{lc}
\hline Growth stage treatment & Soil moisture content (\%) \\
\hline Control & $20.7 \pm 1.0$ \\
Pre-flowering Drought & $15.3 \pm 0.7^{\mathrm{a}}$ \\
Drought $+\mathrm{S}$ & $15.5 \pm 0.9^{\mathrm{b}}$ \\
Flowering Drought & $13.2 \pm 0.6^{\mathrm{ab}}$ \\
Drought $+\mathrm{S}$ & $16.1 \pm 0.8^{\mathrm{ab}}$ \\
Pod-filling Drought & $10.0 \pm 0.5^{\mathrm{abc}}$ \\
Drought $+\mathrm{S}$ & $11.03 \pm 0.6^{\mathrm{ac}}$ \\
\hline
\end{tabular}

Significant differences are: ${ }^{a}$ vs. Control; ${ }^{b}$ vs. Drought (pre-flowering); ${ }^{c}$ vs. Drought (flowering). 
The vials, covered with plastic caps, were placed in a shaking incubator at a constant temperature of $25^{\circ} \mathrm{C}$ for $6 \mathrm{~h}$ and the electrical conductivity (EC) of the solution was measured (EC1) using an electrical conductivity meter (WTW Cond 330i/SET, Weilheim, Germany). Subsequently, the same vials were kept in water bath shaker at $90^{\circ} \mathrm{C}$ for $2 \mathrm{~h}$, cooled and EC2 was measured. EL was expressed following the formula EL $=\mathrm{EC} 1 / \mathrm{EC} 2 \times 100$.

Membrane lipid peroxidation was estimated in terms of thiobarbituric acid reactive substances (TBARS) contents adopting the method of Dhindsa et al. (1981) as described by Anjum et al. (2013). Briefly, fresh leaves (1.0 g) were ground in liquid nitrogen, mixed with $0.73 \%$ 2-thiobarbituric acid in $12 \%$ trichloroacetic acid, incubated for $30 \mathrm{~min}$ in boiling water, ice-cooled, centrifuged at $1000 \times \mathrm{g}$ for $10 \mathrm{~min}$ at $4^{\circ} \mathrm{C}$ and the absorbance measured in the supernatant at $532 \mathrm{~nm}$. The rate of lipid peroxidation was expressed as nmoles of TBARS formed per gram of fresh weight, using a molar extinction coefficient of $1.55 \times 105 \mathrm{M}^{-1}$ $\mathrm{cm}^{-1}$. Leaf- $\mathrm{H}_{2} \mathrm{O}_{2}$ content was determined following the method of Loreto and Velikova (2001) as adopted and described by Dipierro et al. (2005). In brief, leaf tissues ( $1.0 \mathrm{~g})$ were homogenized in $2 \mathrm{ml}$ of $0.1 \%(\mathrm{w} / \mathrm{v})$ TCA. The homogenate was centrifuged at $12,000 \times \mathrm{g}$ for $15 \mathrm{~min}$ and $0.5 \mathrm{ml}$ of the supernatant were mixed with $0.5 \mathrm{ml}$ of $10 \mathrm{mM} \mathrm{K}$-phosphate buffer $\mathrm{pH} 7.0$ and $1 \mathrm{ml}$ of $1 \mathrm{M} \mathrm{KI}$. The $\mathrm{H}_{2} \mathrm{O}_{2}$ content of the supernatant was evaluated by comparing its absorbance at $390 \mathrm{~nm}$ with a standard calibration curve.

\section{DETERMINATION OF CELLULAR BUFFERS}

Both reduced GSH and AsA were considered as representative cellular redox buffers. The content of reduced glutathione (GSH) was estimated following the method of Anderson (1985). Fresh leaf tissues $(1.0 \mathrm{~g})$ were homogenized in $2 \mathrm{ml}$ of $5 \%(\mathrm{w} / \mathrm{v})$ sulphosalicylic acid at $4{ }^{\circ} \mathrm{C}$. The homogenate was centrifuged at $10,000 \times \mathrm{g}$ for $10 \mathrm{~min}$. To a $0.5 \mathrm{ml}$ of supernatant, $0.6 \mathrm{ml}$ of $\mathrm{K}$ phosphate buffer ( $100 \mathrm{mM}, \mathrm{pH} 7.0)$ and $40 \mu \mathrm{l}$ of $5^{\prime} 5^{\prime}$-dithiobis2-nitrobenzoic acid (DTNB) were added, and absorbance was recorded after $2 \mathrm{~min}$ at $412 \mathrm{~nm}$ on a UV-VIS spectrophotometer (Lambda Bio 20, Perkin Elmer, MA, USA). The method of Law et al. (1983) was followed for estimation of reduced ascorbate (AsA). In brief, fresh leaf $(0.5 \mathrm{~g})$ was homogenized in $2.0 \mathrm{ml}$ of $\mathrm{K}$-phosphate buffer $(100 \mathrm{mM}, \mathrm{pH} 7.0)$ containing $1 \mathrm{mM}$ EDTA and centrifuged at $10,000 \times \mathrm{g}$ for $10 \mathrm{~min}$. To a $1.0 \mathrm{ml}$ of supernatant, $0.5 \mathrm{ml}$ of $10 \%(\mathrm{w} / \mathrm{v})$ trichloroactetic acid (TCA) was added, thoroughly mixed and incubated for $5 \mathrm{~min}$ at $4^{\circ} \mathrm{C}$. Then, $0.5 \mathrm{ml}$ of $\mathrm{NaOH}(0.1 \mathrm{M})$ was mixed with $1.5 \mathrm{ml}$ of the above solution and centrifuged at $5000 \times \mathrm{g}$ for $10 \mathrm{~min}$ at $20^{\circ} \mathrm{C}$. The aliquot thus obtained was equally distributed into two separate microfuge tubes $(750 \mu \mathrm{l}$ each). For estimation of AsA, $200 \mu \mathrm{l}$ of K-phosphate buffer ( $150 \mathrm{mM}, \mathrm{pH} 7.4$ ) was added to $750 \mu \mathrm{l}$ of aliquot. For DHA estimation, $750 \mu \mathrm{l}$ of aliquot was added to $100 \mu \mathrm{l}$ of 1,4-dithiothreitol (DTT), followed by vortex-mixing, incubation for $15 \mathrm{~min}$ at $20^{\circ} \mathrm{C}$, and addition of $100 \mu \mathrm{l}$ of $0.5 \%(\mathrm{w} / \mathrm{v})$ NEM. Both the microfuge tubes were then incubated for $30 \mathrm{~s}$ at room temperature. To each sample tube, $400 \mu \mathrm{l}$ of $10 \%$ (w/v) TCA, $400 \mu \mathrm{l}$ of $\mathrm{H}_{3} \mathrm{PO}_{4}$, $400 \mu \mathrm{l}$ of $4 \%(\mathrm{w} / \mathrm{v})$ bipyridyl dye (N'N-dimethyl bipyridyl) and $200 \mu \mathrm{l}$ of $3 \%(\mathrm{w} / \mathrm{v}) \mathrm{FeCl}_{3}$ were added and thoroughly mixed.
Absorbance was recorded at $525 \mathrm{~nm}$ after incubation for $1 \mathrm{~h}$ at $37^{\circ} \mathrm{C}$.

\section{$\mathrm{K}, \mathrm{S}$, AND Mg CONTENT DETERMINATIONS}

The method of Lindner (1944) was followed to estimate K content in digested samples using flame photometry; whereas, for $\mathrm{S}$ determination, $100 \mathrm{mg}$ of dried fine powder of leaf was digested in a mixture of concentrated $\mathrm{HNO}_{3}$ and $60 \% \mathrm{HClO}_{4}(85: 1, \mathrm{v} / \mathrm{v})$ and the content of sulfate was estimated using the turbidimetric method of Chesnin and Yien (1950). Leaf $\mathrm{Mg}$ content was determined by digesting samples in $5 \mathrm{ml}$ of $96 \% \mathrm{H}_{2} \mathrm{SO}_{4}$ and $3 \mathrm{ml}$ of $30 \% \mathrm{H}_{2} \mathrm{O}_{2}$ at $270^{\circ} \mathrm{C}$; thereafter, $\mathrm{Mg}$ content was assayed by atomic absorption spectrometry at $285.2 \mathrm{~nm}$ wavelengths.

\section{DATA ANALYSIS}

SPSS (PASW statistics 18, Chicago, IL, USA) for Windows was used for statistical analysis. One-Way analysis of variance (ANOVA) was performed, followed by all pairwise multiple comparison procedures (Tukey test). Mann-Whitney $U$-test and Levene's test were performed in order to check the normal distribution and the homogeneity of variances, respectively. The data are expressed as mean values $\pm \mathrm{SD}$ of five independent experiments with at least five replicates for each. The significance level was set at $P \leq 0.05$.

\section{RESULTS}

Significant results related to plant growth, photosynthetic functions, soluble-protein content, oxidative stress, cellular reducing buffers, plant mineral nutrients, and yield attributes are presented here, highlighting the significant changes observed at different (pre-flowering, flowering, and pod-filling) stages of plant growth.

\section{PLANT GROWTH AND PHOTOSYNTHETIC FUNCTIONS}

Under drought stress, plant growth, in terms of leaf area and plant dry mass, decreased significantly at pre-flowering stage (vs. control, C). On application of S, significant change was noted in the drought-induced reduction in leaf area only. Drought stress imposed during pre-flowering stage also caused significant decrease in photosynthetic functions (viz., photosynthetic rate, $\mathrm{Pn}$; stomatal conductance, $\mathrm{Gs}$; intercellular $\mathrm{CO}_{2}, \mathrm{C} i$; chlorophyll content), as compared with the control. Supplementation of $\mathrm{S}$ significantly increased the drought-induced reductions in $P n, G s$, and Ci (Tables 2, 3).

During the flowering/reproductive stage, significant decrease in leaf area and plant dry mass was perceptible under drought stress alone (vs. C), whereas S application significantly increased the drought-induced reductions in these parameters. $P n, \mathrm{Gs}, \mathrm{Ci}$ and the chlorophyll content displayed significant decreases due to drought stress (vs. C); whereas, supplementation of S improved these traits (vs. drought at flowering). During the pod-filling stage, leaf area and plant dry mass decreased significantly due to imposition of drought stress (vs. C) and S application deepened the decline in leaf area and plant dry mass. Likewise, $\mathrm{Pn}$, $G s$ and $\mathrm{C} i$ and chlorophyll content displayed significant decreases due to drought stress imposed at the pod-filling stage (vs. C). The decrease in $\mathrm{Pn}, \mathrm{Ci}$ and chlorophyll was significantly ameliorated with S supplementation (Tables 2, 3). 


\section{OXIDATIVE STRESS AND MODULATION OF THE POOLS OF CELLULAR REDOX BUFFERS}

With-holding water for 5-days during pre-flowering stage led to significant increases in electrolyte leakage (EL) and in the contents of thiobarbituric-acid-reactive substances (TBARS) and $\mathrm{H}_{2} \mathrm{O}_{2}$ (vs. C). However, S-application significantly decreased the impact of drought stress-impact at pre-flowering by reducing EL and the contents of TBARS and $\mathrm{H}_{2} \mathrm{O}_{2}$ (Figure 1). The pools of cellular redox buffers namely reduced ascorbate (AsA) and glutathione (GSH) declined significantly due to pre-flowering drought stress (vs. C); S-supplementation was insignificant to mitigate these declines. Oxidative stress traits such as EL, and the contents of TBARS and $\mathrm{H}_{2} \mathrm{O}_{2}$ significantly increased due to drought stress created at flowering stage (vs. C); however, S-application significantly decreased this drought-caused oxidative stress. In contrast,

Table 2 | Leaf area $\left(\mathrm{cm}^{2}\right.$ plant $^{-1}$ ) and plant dry mass (g plant $\left.{ }^{-1}\right)$ in mungbean (Vigna radiata) as influenced by drought stress and by drought + sulfur (S) application ( $\mathrm{mg} \mathrm{kg}^{-1}$ soil) at pre-flowering, flowering, and pod-filling stages.

\begin{tabular}{llcc}
\hline Growth stage & Treatment & Leaf area & Plant dry mass \\
\hline Pre-flowering & Control & $147.0 \pm 10.1$ & $1.8 \pm 0.3$ \\
& Drought & $87.02 \pm 9.1^{\mathrm{a}}$ & $1.0 \pm 0.2^{\mathrm{a}}$ \\
& Drought $+\mathrm{S}$ & $140.6 \pm 9.3^{\mathrm{b}}$ & $1.3 \pm 0.4$ \\
\hline Flowering & Control & $362.5 \pm 14.5$ & $9.2 \pm 0.6$ \\
& Drought & $291.8 \pm 13.2^{\mathrm{a}}$ & $6.2 \pm 0.3^{\mathrm{a}}$ \\
& Drought $+\mathrm{S}$ & $360.6 \pm 14.4^{\mathrm{C}}$ & $8.02 \pm 0.6^{\mathrm{ac}}$ \\
\hline Pod-filling & Control & $303.1 \pm 10.6$ & $16.6 \pm 1.02$ \\
& Drought & $192.2 \pm 8.5^{\mathrm{a}}$ & $10.6 \pm 0.8^{\mathrm{a}}$ \\
& Drought $+\mathrm{S}$ & $185.2 \pm 7.9^{\mathrm{ad}}$ & $16.1 \pm 0.8^{\mathrm{d}}$ \\
\hline
\end{tabular}

Values are the means of five replicates \pm standard deviation. Significant differences within the same growth stage are: ${ }^{a}$ vs. Control; ${ }^{b}$ vs. Drought (pre-flowering); ${ }^{c}$ vs. Drought (flowering); ${ }^{d}$ vs. Drought (pod-filling). the contents of reduced AsA and GSH contents declined significantly (vs. C) due to drought stress at this stage, and supplementation of S significantly ameliorated these declines. Drought stress imposed at pod-filling stage significantly increased EL and the contents of TBARS and $\mathrm{H}_{2} \mathrm{O}_{2}$ (vs. C); whereas S-application significantly reduced the levels of $\mathrm{H}_{2} \mathrm{O}_{2}$ and EL elevated by drought at this stage. The reductions in AsA and GSH contents due to the drought stress imposed at pod-filling stage were insignificant (vs. $\mathrm{C}$ ), and the effect of S supplementation in mitigating the impact of drought stress was also insignificant (Figure 2).

\section{MINERAL NUTRIENTS}

Plant nutrients, such as $\mathrm{K}, \mathrm{S}$, and $\mathrm{Mg}$, displayed significant reductions due to drought stress imposed at pre-flowering stage (vs. C); however, no significant difference was observed when droughtstressed plants were supplemented with S. Drought imposition during flowering stage caused significant reduction in $\mathrm{K}, \mathrm{S}$, and $\mathrm{Mg}$ levels in the leaf tissue (vs. C); whereas their contents significantly increased when plants facing drought at flowering stage were supplemented with S. Among the plant nutrients studied, only $\mathrm{K}$ content displayed a significant reduction due to drought at pod-filling stage (vs. C); whereas S and Mg contents did not differ significantly under the stress of drought alone or drought + $\mathrm{S}$ imposed at pod-filling stage (vs. C). Moreover, the $\mathrm{K}$ content significantly increased when drought-stressed plants were supplemented with S (Table 4).

\section{DISCUSSION \\ PLANT GROWTH AND PHOTOSYNTHETIC FUNCTIONS}

Plant growth is the outcome of coordination of major physiological/biochemical processes in plants. In the present study, plant dry mass and leaf area showed a significant relationship with the severity of water deficit stress, irrespective of the phase of plant ontogeny. Earlier, plant growth in terms of dry mass accumulation and leaf area has been used as a tool for the assessment of crop productivity (Sundaravalli et al., 2005; Anjum et al., 2008a). Cell division, enlargement and differentiation and also the plant

Table 3 | Net photosynthetic rate $\left(\mathrm{Pn} ; \mu \mathrm{mol} \mathrm{CO} \mathrm{Cm}^{-1} \mathrm{~s}^{-1}\right)$, stomatal conductance $\left(\mathrm{Gs} ; \mathrm{mol} \mathrm{m}^{-2} \mathrm{~s}^{-1}\right)$, intercellular $\mathrm{CO}_{2}$ concentration $(\mathrm{Ci} ; \mu \mathrm{mol}$ $\mathrm{mol}^{-1}$ ), chlorophyll (Chl) content ( $\mathrm{mg} \mathrm{g}^{-1}$ fresh weight, f.w.) and soluble protein content ( $\mathrm{mg} \mathrm{g}^{-1}$ f.w.) in mungbean (Vigna radiata), as influenced by drought stress and by drought + sulfur (S) application ( $\mathrm{mg} \mathrm{kg}^{-1}$ soil) at pre-flowering, flowering, and pod-filling stages.

\begin{tabular}{|c|c|c|c|c|c|}
\hline Growth stage & Treatment & Pn & Gs & $\mathbf{C i}$ & Chl \\
\hline Pre-flowering & Drought & $9.6 \pm 1.3^{\mathrm{a}}$ & $0.25 \pm 0.05^{a}$ & $174.0 \pm 33.1^{\mathrm{a}}$ & $0.76 \pm 0.1^{\mathrm{a}}$ \\
\hline \multirow[t]{2}{*}{ Flowering } & Control & $20.0 \pm 3.4$ & $0.70 \pm 0.2$ & $206.9 \pm 39.3$ & $1.4 \pm 0.2$ \\
\hline & Drought & $10.7 \pm 3.2^{\mathrm{a}}$ & $0.48 \pm 0.1^{a}$ & $154.9 \pm 29.4^{\mathrm{a}}$ & $0.8 \pm 0.07^{a}$ \\
\hline \multirow[t]{3}{*}{ Pod-filling } & Control & $14.8 \pm 4.4$ & $0.47 \pm 0.1$ & $189.4 \pm 36.0$ & $1.3 \pm 0.2$ \\
\hline & Drought & $10.2 \pm 3.5^{a}$ & $0.4 \pm 0.1$ & $178.3 \pm 34.0^{\mathrm{a}}$ & $0.7 \pm 0.06^{a}$ \\
\hline & Drought $+\mathrm{S}$ & $11.6 \pm 4.3^{\mathrm{ad}}$ & $0.6 \pm 0.1^{\mathrm{ad}}$ & $195.2 \pm 37.0^{\mathrm{ad}}$ & $1.03 \pm 0.1^{d}$ \\
\hline
\end{tabular}

Values are the means of five replicates \pm standard deviation. Significant differences within the same growth stage are: ${ }^{a}$ vs. Control; ${ }^{b}$ vs. Drought (pre-flowering); ${ }^{c}$ vs. Drought (flowering); ${ }^{d}$ vs. Drought (pod-filling). 


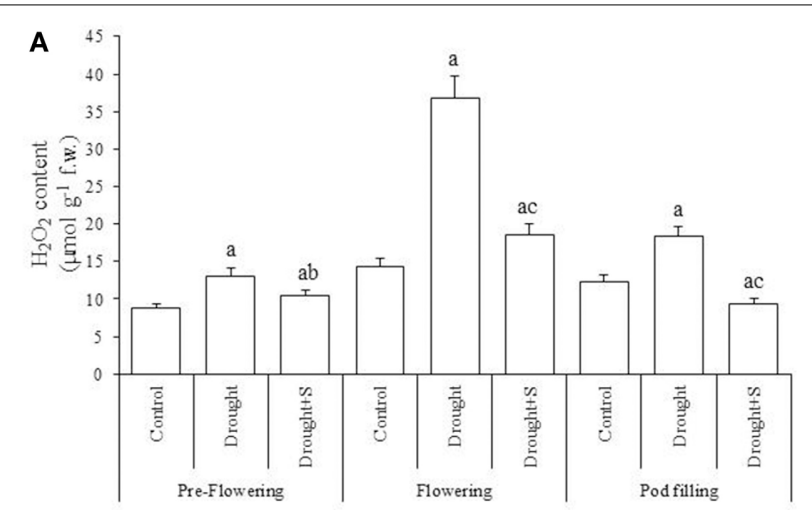

B
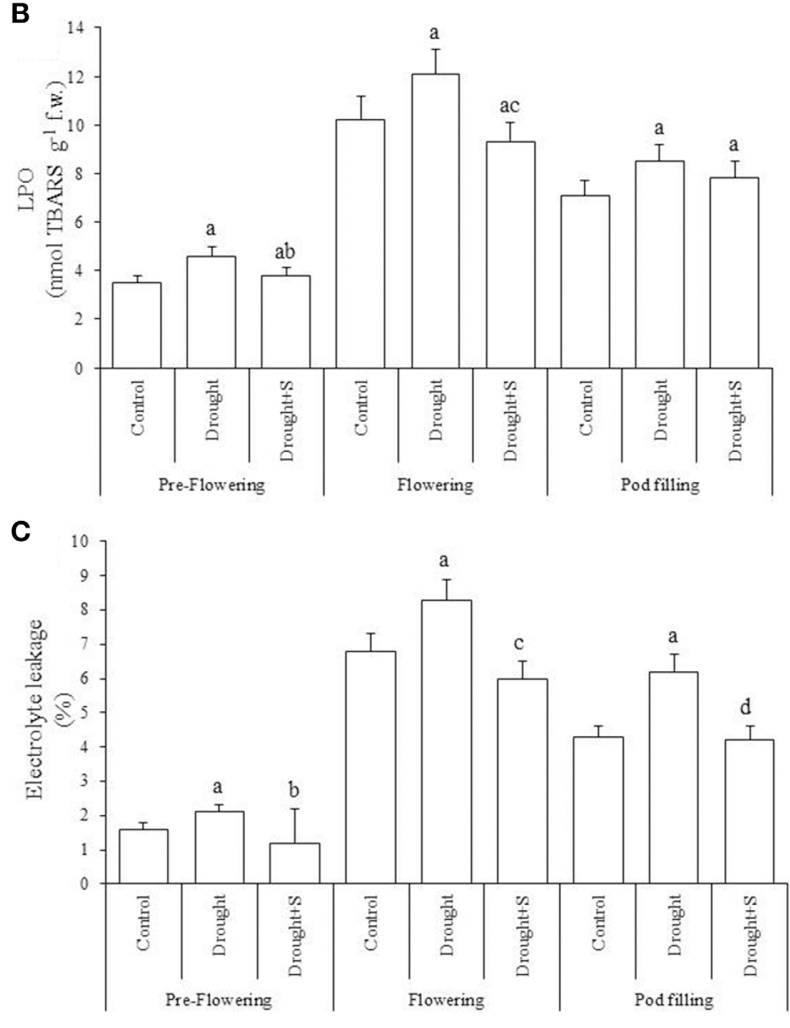

Plant growth stages/Drought or Drought $+\mathrm{S}$

FIGURE 1 | Levels of $\mathrm{H}_{2} \mathrm{O}_{2}$ (nmol $\mathrm{g}^{-1}$ fresh weight, f.w.) (A), lipid peroxidation (LPO; nmol thiobarbituric acid reactive substances, TBARS $\mathrm{g}^{-1}$ f.w.) (B) and electrolyte leakage (\%) (C) in the mungbean (Vigna radiata) leaf as influenced by drought stress and by drought + sulfur (S) application ( $\mathrm{mg} \mathrm{kg}^{-1}$ soil) at pre-flowering, flowering, and pod-filling stages of plant growth. Values are the means of five replicates \pm standard deviation. Significant differences within the same growth stage are: ${ }^{a} v s$. Control; ${ }^{b} v s$. Drought (pre-flowering); ${ }^{c} v s$. Drought (flowering); and ${ }^{d}$ vs. Drought (pod-filling).

genetic make-up are significantly influenced by water-deficit stress, which in turn affects plant growth (Aref et al., 2013). In the present study, previously mentioned processes might be impacted by drought tress severely during vegetative/flowering stage which coincides with drought-mediated considerable decreases in leaf area and photosynthesis, as observed earlier also (Sundaravalli et al., 2005; Anjum et al., 2008a; Husen et al., 2014). However, the
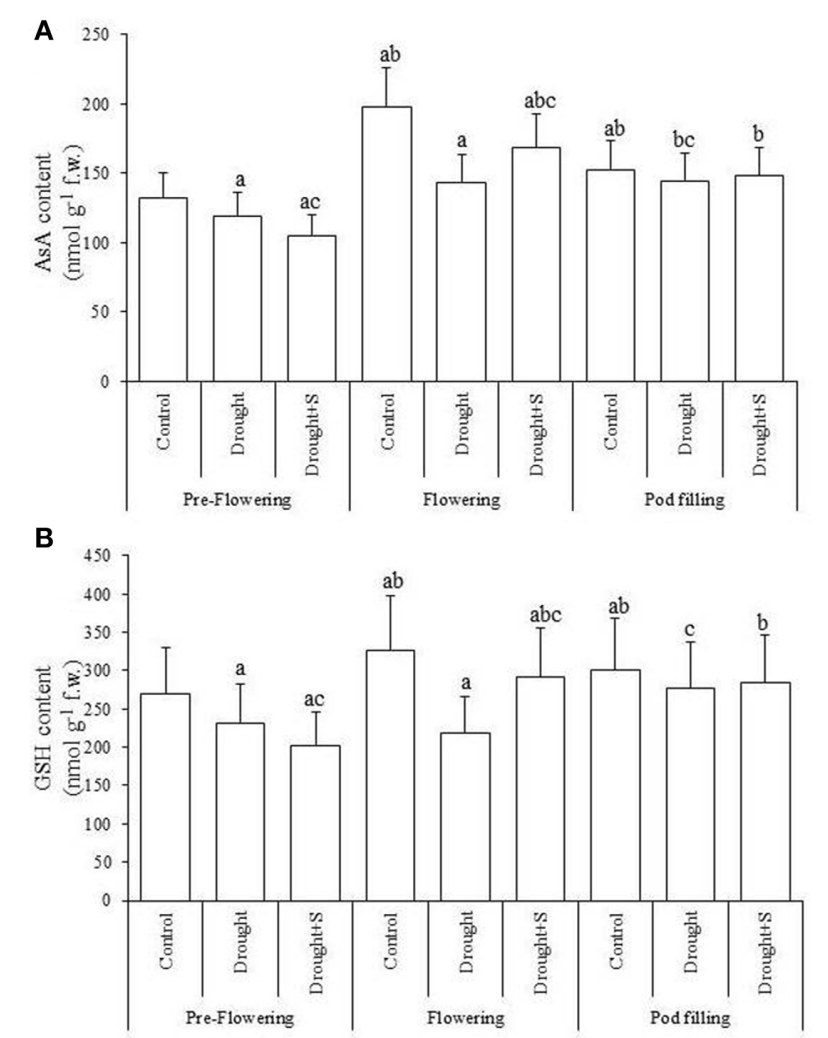

Plant growth stages/Drought or Drought $+\mathrm{S}$

FIGURE 2 | The reduced ascorbate (AsA) (A) and reduced glutathione (GSH) (B) contents ( $\mathrm{nmol} \mathrm{^{-1 }}$ fresh weight) in the mungbean (Vigna radiata) leaf as influenced by drought stress and sulfur (S) application ( $\mathrm{mg} \mathrm{kg}^{-1}$ soil) at pre-flowering, flowering, and pod-filling stages of plant growth. Values are the means of five replicates \pm standard deviation. Significant differences within same growth stage are: ${ }^{a} \mathrm{vs}$. Control; ${ }^{b}$ vs. Drought (pre-flowering); ${ }^{c} v s$. Drought (flowering); and ${ }^{d} v s$. Drought (pod-filling).

drought-induced huge reduction in leaf area (a major component of plant growth) may be a strategy that plants adopt to adjust with water-deficit stress. Earlier, the reduced leaf-expansion/area was evidenced to conserve the internal water/moisture through the reduced rate of transpiration (reviewed by Mahajan and Tuteja, 2005).

Photosynthesis $(\mathrm{P} n)$ and its related variables ( $G s, \mathrm{C} i$, chlorophyll content) are highly regulated multi-step processes and exhibit great sensitivity to drought stress (Zlatev et al., 2006; Lawlor and Tezara, 2009; Husen et al., 2014). In the current study, drought stress alone significantly decreased $\mathrm{P} n, \mathrm{G} s, \mathrm{C} i$ and chlorophyll content irrespective of the plant ontogenetic stages. In fact, photosynthesis and its related variables are tightly interwoven and hence changes in one component significantly affect the performance of others (Lawlor and Tezara, 2009). Our findings on the drought stress-accrued reductions in $\mathrm{Gs}$ and leaf $\mathrm{C} i$ coincide with those of Zlatev et al. (2006) and Meyer and Genty (1998), who considered Gs as the major factor for controlling $\mathrm{C} i$ and hence the $\mathrm{P} n$. Additionally, unavailability of chlorophyll 


\begin{tabular}{|c|c|c|c|c|}
\hline Growth stage & Treatment & $\mathbf{K}$ & S & $\mathbf{M g}$ \\
\hline \multirow[t]{3}{*}{ Pre-Flowering } & Control & $3.3 \pm 0.3$ & $1.6 \pm 0.2$ & $1.6 \pm 0.2$ \\
\hline & Drought & $2.2 \pm 0.2^{a}$ & $1.2 \pm 0.1^{\mathrm{a}}$ & $0.7 \pm 0.1^{a}$ \\
\hline & Drought $+S$ & $2.4 \pm 0.2^{\mathrm{a}}$ & $1.6 \pm 0.2$ & $0.9 \pm 0.1^{\mathrm{a}}$ \\
\hline \multirow[t]{3}{*}{ Flowering } & Control & $5.6 \pm 0.5$ & $2.45 \pm 0.2$ & $2.1 \pm 0.2$ \\
\hline & Drought & $3.0 \pm 0.3^{a}$ & $0.2 \pm 0.02^{a}$ & $0.8 \pm 0.1^{a}$ \\
\hline & Drought $+S$ & $5.2 \pm 0.4^{c}$ & $1.7 \pm 0.13^{c}$ & $2.0 \pm 0.2^{c}$ \\
\hline \multirow[t]{3}{*}{ Pod-filling } & Control & $3.1 \pm 0.3$ & $1.3 \pm 0.1$ & $1.8 \pm 0.2$ \\
\hline & Drought & $2.4 \pm 0.2^{a}$ & $1.1 \pm 0.1$ & $1.4 \pm 0.2$ \\
\hline & Drought $+S$ & $3.0 \pm 0.3^{d}$ & $1.3 \pm 0.1$ & $1.8 \pm 0.2$ \\
\hline
\end{tabular}

Values are the means of five replicates \pm standard deviation. Significant differences within same growth stage are: ${ }^{a}$ vs. Control; ${ }^{b}$ vs. Drought (pre-flowering); ${ }^{c}$ vs. Drought (flowering); ${ }^{d}$ vs. Drought (pod-filling).

also contributes to drought-induced decrease in $\mathrm{Pn}$ (Lawlor and Tezara, 2009). The drought-induced decrease in chlorophyll content has been reported earlier also due to reduction in the lamellar content of the light-harvesting chlorophyll a/b protein, inhibition in biosynthesis of chlorophyll-precursors and/or degradation of chlorophyll (Khanna-Chopra et al., 1980). Our findings on drought-mediated decrease in $\mathrm{P} n, \mathrm{Gs}, \mathrm{C} i$ and the content of chlorophyll confirm some earlier reports (Khanna-Chopra et al., 1980; Anjum et al., 2008a; Husen et al., 2014).

Regardless of irrigation treatments, our results also revealed that S-application significantly increased the growth and chlorophyll content and $P n$. It was more effective when applied at flowering stage of the plant. The adequate and balanced supply of mineral nutrients has been shown to play a vital role in sustaining food security (Cakmak, 2005). S is involved in the light reaction of photosynthesis as an integral part of ferredoxin, a non-haem iron-sulfur protein (Marschner, 1995). Additionally, it plays essential roles in mechanisms like vitamin co-factors, GSH in redox homeostasis, and detoxification of xenobiotics (Anjum et al., 2012b). The S requirement by plants varies with growth stage and with species, varying normally between 0.1 and $1.5 \%$ of dry weight. Anjum et al. (2008b) suggested that adequate S supply may improve the pools of these compounds in plants to a great extent that may lead to increased photosynthetic efficiency, dry mass and crop yield. Sufficient S supplies improved photosynthesis and growth of Brassica juncea through regulating $\mathrm{N}$ assimilation (Khan et al., 2005). The maximum utilization of S in Brassica campestris crop takes place when applied at flowering stage (Ahmad et al., 2005; Anjum, 2006). Application of S increased the seed yield and attributing characters in other crops also (Anjum et al., 2012b).

\section{OXIDATIVE STRESS AND MODULATION OF THE POOLS OF CELLULAR REDOX BUFFERS AND MINERAL NUTRIENTS}

Production of ROS, such as $\mathrm{H}_{2} \mathrm{O}_{2}$, is mediated by $\mathrm{O}_{2}$ reduction and subsequent oxidative damages in drought-exposed plants
(Khanna-Chopra and Selote, 2007; Anjum et al., 2012a). Plant membrane is regarded as the first target of many plant stresses due to increase in its permeability and loss of integrity under environmental stresses including the drought stress (Candan and Tarhan, 2003). In the present study, the drought-stress sensitivity of the reproductive phase of drought-exposed $V$. radiata was evidenced by significantly high levels of $\mathrm{H}_{2} \mathrm{O}_{2}$, the content of TBARS (the cytotoxic products of lipid peroxidation and indicator of extent of stress-led ROS-mediated high oxidative stress) and the EL (the measure of stress-mediated changes in membrane leakage and injury) at flowering stage, followed by pre-flowering and postflowering stages. These results are in close agreement with the findings of Qureshi et al. (2007). Earlier, the least peroxidation of membrane lipids and the ability of cell membranes to tightly control the rate of ion movement in and out of cells have been used as tests of damage to a great range of tissues (Candan and Tarhan, 2003). However, the drought-stressed plants exhibited least contents of $\mathrm{H}_{2} \mathrm{O}_{2}$, TBARS and percent EL, when supplemented with $\mathrm{S}$ at their flowering and pod-filling stages. These results suggested that the S-mediated decrease in contents of $\mathrm{H}_{2} \mathrm{O}_{2}$, TBARS and percent EL depends on application of $\mathrm{S}$ to drought-stressed plants at appropriate growth stage when $S$ is efficiently and differentially utilized to strengthen plants to withstand the enhanced lipid peroxidation and subsequent leakage of electrolytes due to elevated levels of $\mathrm{H}_{2} \mathrm{O}_{2}$. Thus, S-application protected differentially the drought-stressed plants against $\mathrm{H}_{2} \mathrm{O}_{2}$-mediated localized oxidative damage, disruption of metabolic functions, LPO and leakage of electrolytes (Zlatev et al., 2006). Our observations on drought alone-mediated significant increases in $\mathrm{H}_{2} \mathrm{O}_{2}$ content, lipid peroxidation (in terms of TBARS content) and percent EL in $V$. radiata plants coincide with the findings of Sreenivasulu et al. (2000) and Selote and Khanna-Chopra (2006) on different crop plants.

Plant resistance to stresses is closely associated with the efficiency of the antioxidant defense system (comprising both enzymatic and non-enzymatic components of AsA-GSH pathway) in the maintenance of the balance between the basal production of ROS and their elimination (Anjum et al., 2010, 2012c). In this perspective, AsA and GSH are important water-soluble non-enzymatic antioxidants and major cellular redox buffers in plants (Anjum et al., 2010, 2012c, 2014). Both are interlinked in terms of their physiological role in AsA-GSH pathway for effective elimination of ROS (such as $\mathrm{H}_{2} \mathrm{O}_{2}$ ) in plant cells (Anjum et al., 2010, 2012a,c). Contrary to an earlier report (Shehab et al., 2010) on drought-induced increase in AsA and GSH levels in different plant species, our study revealed a significant decrease in the contents of both AsA and GSH in V. radiata, irrespective of the growth stage at which the drought stress was imposed. However, our findings are in conformity with those of Khanna-Chopra and Selote (2007) on drought-exposed Triticum aestivum. The application of S improved the AsA and GSH contents and was thus beneficial when applied to drought-stressed plants at their flowering or post-flowering stages. It was, therefore, significant for protection of $V$. radiata against ROS-mediated oxidative stress. This substantiates our earlier report suggesting improved AsA and GSH contents in Cd-stressed Brassica campestris plants by S supplementation (Anjum et al., 2008b). However, it is imperative to 
mention here that exhibition of higher levels of AsA and GSH in plants receiving drought stress $+\mathrm{S}$ supply at pod-filling stage may be due to S-mediated maintenance of elevated activities of AsAGSH-regenerating enzymes such as dehydroascorbate reductase, monodehydroascorbate reductase, and GSH reductase (Eltayeb et al., 2007; Anjum et al., 2008b). Moreover, as AsA and GSH are key players in cellular redox homeostasis; the S-mediated improvement in their reduced pools must help plants to run normally the ascorbate peroxide-dependent $\mathrm{H}_{2} \mathrm{O}_{2}$ metabolism under drought-stress conditions. Therefore, $\mathrm{S}$ application mitigated, although partially, the drought-induced decrease in AsA content by maintaining elevated activities of dehydroascorbate reductase and monodehydroascorbate reductase (data not shown)-the key components in maintaining the reduced pool of AsA and hence the plant tolerance to oxidative stress (Eltayeb et al., 2007). Considering $\mathrm{K}, \mathrm{S}$, and $\mathrm{Mg}$ responses to drought and $\mathrm{S}$, the uptake of the available nutrient ions dissolved in the soil solution by

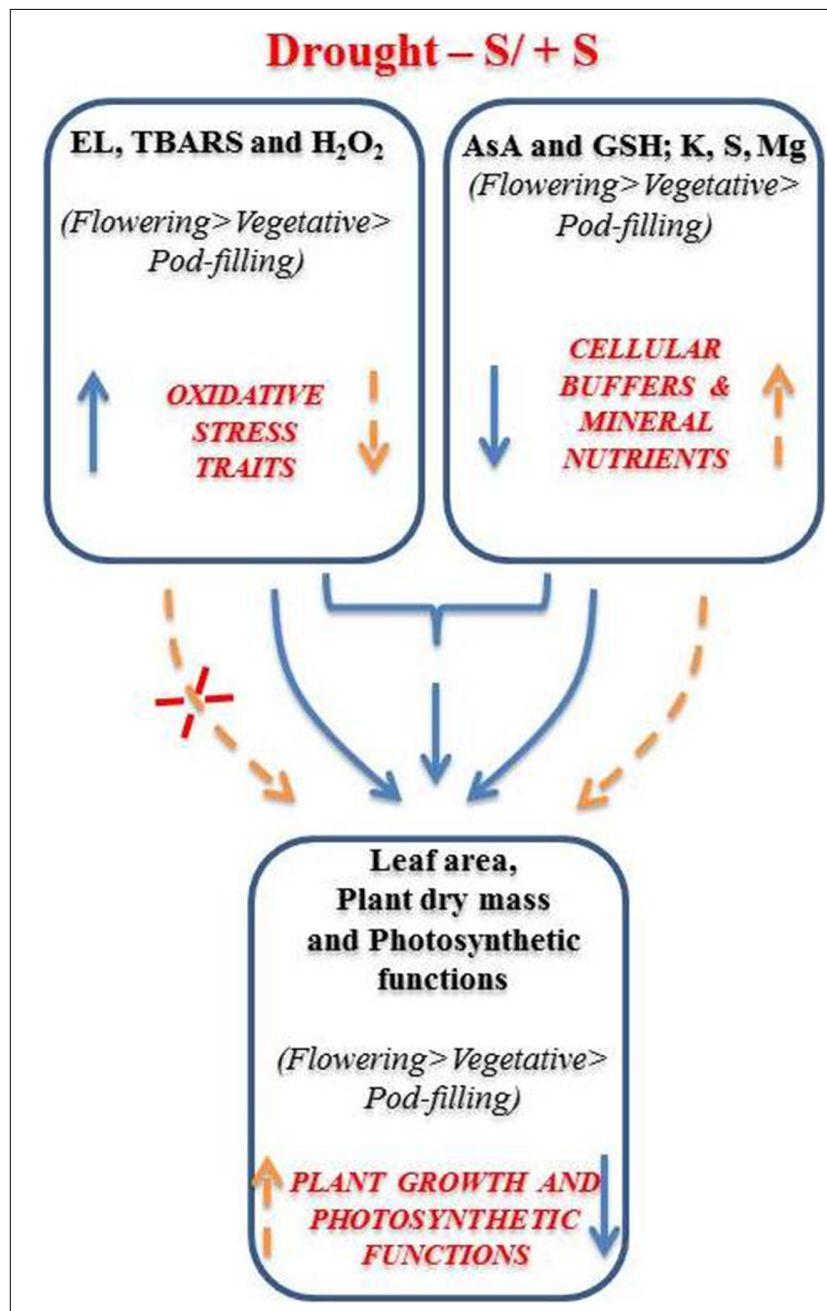

FIGURE 3 | Schematic representation of drought stress impacts and the role of sulfur (S) in mungbean (Vigna radiata) during its ontogeny. Complete and broken lines indicate respectively drought alone and drought $+\mathrm{S}$ conditions; whereas, increase and decrease have been indicated by the up and down arrows respectively. plants depends upon water flow through the soil-root-shoot pathway. It also depends on root growth and nutrient mobility in the soil (Fageria et al., 2002). In this study, drought stress significantly impacted the contents of $\mathrm{K}, \mathrm{S}$, and $\mathrm{Mg}$ in leaves contingent upon the plant-growth stage exposed. However, as reported also in earlier studies (Abdin et al., 2003; Malvi, 2011), a synergistic interaction of $\mathrm{S}$ with $\mathrm{K}$ and $\mathrm{Mg}$ was revealed herein, where $\mathrm{S}$ application ameliorated drought-induced reductions in the leaf $\mathrm{K}, \mathrm{S}$, and $\mathrm{Mg}$ contents, maximally when applied at reproductive stage.

\section{CONCLUSIONS}

Drought stress in isolation enhanced ROS generation and decreased the cellular redox buffers (AsA and GSH) and eventually hampered photosynthetic functions. These results were significant at flowering stage, followed by the pre-flowering and post-flowering (pod-filling) stages (Figure 3). However, improvements in these parameters due to $\mathrm{S}$ application was apparent (at the flowering/reproductive stage), which enhanced the pools of cellular redox buffers (AsA and GSH), which in turn managed a balance between the production and scavenging of $\mathrm{H}_{2} \mathrm{O}_{2}$ and stabilized the cell membrane by decreasing LPO (Figure 3). Overall, the study inferred that supplementation of $\mathrm{S}$ to drought-exposed plants at their flowering stage can improve their growth, photosynthesis and related variables via efficiently being utilized, and in turn managing the pools of AsA and GSH, and subsequently controlling the drought-accrued oxidative stress.

\section{ACKNOWLEDGMENTS}

Partial financial support received from the Hamdard National Foundation (HNF), New Delhi, India (DSW/HNF-18/2006) and the Portuguese Foundation for Science and Technology (FCT) (SFRH/BPD/64690/2009; SFRH/BPD/84671/2012) is gratefully acknowledged.

\section{REFERENCES}

Abdin, M. Z., Ahmad, A., Khan, N., Khan, I., Jamal, A., and Iqbal, M. (2003). "Sulphur interaction with other nutrients," in Sulphur in Plants, eds Y. Abrol and A. Ahmad (Dordrecht: Kluwer Academic Publishers), 359-374. doi: 10.1007/978-94-017-0289-8_20

Ahmad, A., Khan, I., Anjum, N. A., Diva, I., Abdin, M. Z., and Iqbal, M. (2005). Effect of timing of sulfur fertilizer application on growth and yield of rapeseed. J. Plant Nutr. 28, 1049-1059. doi: 10.1081/PLN-200058905

Anderson, M. E. (1985). Determination of glutathione and glutathione disulfides in biological samples. Methods Enzymol. 113, 548-570. doi: 10.1016/S0076$6879(85) 13073-9$

Anjum, N. A. (2006). Effect of Abiotic Stresses on Growth and Yield of Brassica campestris L. and Vigna radiata (L.) Wilczek under Different Sulfur Regimes. Ph.D. thesis, New Delhi: Jamia Hamdard.

Anjum, N. A., Ahmad, I., Mohmood, I., Pacheco, M., Duarte, A. C., Pereira, E., et al. (2012c). Modulation of glutathione and its related enzymes in plants' responses to toxic metals and metalloids - a review. Environ. Exp. Bot. 75, 307-324. doi: 10.1016/j.envexpbot.2011.07.002

Anjum, N. A., Ahmad, I., Rodrigues, S., Henriques, B., Cruz, N., Coelho, C. et al. (2013). Eriophorum angustifolium and Lolium perenne metabolic adaptations to metals- and metalloids-induced anomalies in the vicinity of a chemical industrial complex. Environ. Sci. Pollut. Res. 20, 568-581. doi: 10.1007/s11356012-1062-2

Anjum, N. A., Gill, S. S., Gill, R., Hasanuzzaman, M., Duarte, A. C., Pereira, E., et al. (2014). Metal/metalloid stress tolerance in plants: role of ascorbate, 
its redox couple and associated enzymes. Protoplasma 251, 1265-1283. doi: 10.1007/s00709-014-0636-x

Anjum, N. A., Gill, S. S., Umar, S., Ahmad, I., Duarte, A. C., and Pereira, E. (2012b). Improving growth and productivity of oleiferous Brassicas under changing environment: significance of nitrogen and sulphur nutrition, and underlying mechanisms. Sci. World J. 2012:657808. doi: 10.1100/2012/657808

Anjum, N. A., Umar, S., and Ahmad, A. (2012a). Oxidative Stress in Plants: Causes, Consequences and Tolerance. New Delhi: IK International Publishing House Pvt. Ltd.

Anjum, N. A., Umar, S., Ahmad, A., Iqbal, M., and Khan, N. A. (2008b). Sulphur protects mustard (Brassica campestris L.) from cadmium toxicity by improving leaf ascorbate and glutathione. Plant Growth Regul. 54, 271-279. doi: 10.1007/s10725-007-9251-6

Anjum, N. A., Umar, S., Ahmad, A., Iqbal, M., and Khan, N. A. (2008c). Ontogenic variation in response of Brassica campestris L. to cadmium toxicity. J. Plant Interact. 3, 189-198. doi: 10.1080/17429140701823164

Anjum, N. A., Umar, S., and Chan, M. T. (2010). Ascorbate-Glutathione Pathway and Stress Tolerance in Plants. Dordrecht: Springer. doi: 10.1007/978-90-4819404-9

Anjum, N. A., Umar, S., Iqbal, M., and Khan, N. A. (2008a). Growth characteristics and antioxidant metabolism of moongbean genotypes differing in photosynthetic capacity subjected to water deficit stress. J. Plant Interact. 3, 127-136. doi: 10.1080/17429140701810732

Aref, M. I., Ahmed, A. I., Khan, P. R., El-Atta, H., and Iqbal, M. (2013). Droughtinduced adaptive changes in the seedling anatomy of Acacia ehrenbergiana and Acacia tortilis subsp. raddiana. Trees 27, 959-971. doi: 10.1007/s00468-0130848-2

Bradford, M. M. (1976). A rapid and sensitive method for the quantitation of microgram quantities of protein utilizing the principle of proteindye binding. Anal. Biochem. 72, 248-254. doi: 10.1016/0003-2697(76) 90527-3

Cai, Y., Cao, F., Wei, K., Zhang, G., and Wu, F. (2011). Genotypic dependent effect of exogenous glutathione on Cd-induced changes in proteins, ultrastructure and antioxidant defense enzymes in rice seedlings. J. Hazard. Mater. 192, 1056-1066. doi: 10.1016/j.jhazmat.2011.06.011

Cakmak, I. (2005). The role of potassium in alleviating detrimental effects of abiotic stresses in plants. J. Plant Nutr. Soil Sci. 168, 521-530. doi: 10.1002/jpln.200420485

Candan, N., and Tarhan, L. (2003). The correlation between antioxidant enzyme activities and lipid peroxidation levels in Mentha pulegium organs grown in $\mathrm{Ca}^{2+}, \mathrm{Mg}^{2+}, \mathrm{Cu}^{2+}, \mathrm{Zn}^{2+}$ and $\mathrm{Mn}^{2+}$ stress conditions. Plant Sci. 163, 769-779. doi: 10.1016/S0168-9452(03)00269-3

Chesnin, L., and Yien, C. H. (1950). Turbidimetric determination of available sulphates. Proc. Soil Sci. Soc. Am. 51, 149-151.

Dhindsa, R. H., Plumb-Dhindsa, P., and Thorpe, T. A. (1981). Leaf senescence correlated with increased level of membrane permeability, lipid per oxidation and decreased level of SOD and CAT. J. Exp. Bot. 32, 93-101. doi: 10.1093/jxb/32.1.93

Dipierro, N., Mondelli, D., Paciolla, C., Brunetti, G., and Dipierro, S. (2005). Changes in the ascorbate system in the response of pumpkin (Cucurbita pepo L.) roots to aluminium stress. Plant Physiol. 162, 529-536. doi: 10.1016/j.jplph.2004.06.008

Eltayeb, A. M., Kawano, N., Badawi, G. H., Kaminaka, H., Sanekata, T., Shibahara, T., et al. (2007). Overexpression of monodehydroascorbate reductase in transgenic tobacco confers enhanced tolerance to ozone, salt and polyethylene glycol stresses. Planta 225, 1255-1264. doi: 10.1007/s00425-006-0417-7

Fageria, N. K., Baligar, V. C., and Clark, R. B. (2002). Micronutrients in crop production. Adv. Agron. 77, 185-187. doi: 10.1016/S0065-2113(02) 77015-6

Gill, S. S., Khan, N. A., Anjum, N. A., and Tuteja, N. (2011). Amelioration of cadmium stress in crop plants by nutrients management: morphological, physiological and biochemical aspects. Plant Stress 5, 1-23.

Harb, A., Krishnan, A., Ambavaram, M. M., and Pereira, A. (2010). Molecular and physiological analysis of drought stress in Arabidopsis reveals early responses leading to acclimation in plant growth. Plant Physiol. 154, 1254-1271. doi: $10.1104 /$ pp.110.161752

Hawkesford, M. J. (2000). Plant responses to sulfur deficiency and the genetic manipulation of sulfate transporters to improve S-utilization efficiency. J. Exp. Bot. 51, 131-138. doi: 10.1093/jexbot/51.342.131
Hiscox, J. H., and Israelstam, G. F. (1979). A method for extraction of chlorophyll from leaf tissues without maceration. Can. J. Bot. 57, 1332-1334. doi: 10.1139/b79-163

Husen, A., Iqbal, M., and Aref, I. M. (2014). Water status and leaf characteristics of Brassica carinata under drought stress and re-hydration conditions. Braz. J. Bot. 37, 217-227. doi: 10.1007/s40415-014-0066-1

Khan, N. A., Mobin, M., and Samiullah. (2005). The influence of gibberellic acid and sulfur fertilization rate on growth and S-use efficiency of mustard (Brassica juncea). Plant Soil 270, 269-274. doi: 10.1007/s11104-004-1606-4

Khanna-Chopra, R., Chaturverdi, G., Aggarwal, P., and Sinha, S. (1980). Effect of potassium on growth and nitrate reductase during water stress and recovery in maize. Physiol. Plant 49, 495-500. doi: 10.1111/j.1399-3054.1980. tb03340.x

Khanna-Chopra, R., and Selote, D. S. (2007). Acclimation to drought stress generates oxidative stress tolerance in drought resistant than susceptible wheat cultivar under field conditions. Environ. Exp. Bot. 60, 276-283. doi: 10.1016/j.envexpbot.2006.11.004

Law, M. Y., Charles, S. A., and Halliwell, B. (1983). Glutathione and ascorbic acid in spinach (Spinaceu oleraceu) chloroplasts. The effect of hydrogen peroxide and of paraquat. Biochem. J. 210, 899-903.

Lawlor, D. W., and Tezara, W. (2009). Causes of decreased photosynthetic rate and metabolic capacity in water-deficient leaf cells: a critical evaluation of mechanisms and integration of processes. Ann. Bot. 103, 561-579. doi: 10.1093/aob/mcn244

Lindner, R. C. (1944). Rapid analytical method for some of the more common organic substances of plant and soil. Plant Physiol. 19, 76-84. doi: 10.1104/pp.19.1.76

Loreto, F., and Velikova, V. (2001). Isoprene produced by leaves protects the photosynthetic apparatus against ozone damage, quenches ozone products, and reduces lipid peroxidation of cellular membranes. Plant Physiol. 127, 1781-1787. doi: 10.1104/pp.010497

Lunde, C., Zygadlo, A., Simonsen, H. T., Nielsen, P. L., Blennow, A., and Haldrup, A. (2008). Sulfur starvation in rice: the effect on photosynthesis, carbohydrate metabolism, and oxidative stress protective pathways. Physiol. Plant 134, 508-521. doi: 10.1111/j.1399-3054.2008.01159.x

Mahajan, S., and Tuteja, N. (2005). Cold, salinity and drought stresses: an overview. Arch. Biochem. Biophys. 444, 139-158. doi: 10.1016/j.abb.2005. 10.018

Malvi, U. R. (2011). Interaction of micronutrients with major nutrients with special reference to potassium. Karnataka J. Agric. Sci. 24, 206-109.

Marschner, H. (1995). Mineral Nutrition of Higher Plants, 1st Edn. New York, NY: Academic Press.

Meyer, S., and Genty, B. (1998). Mapping intercellular $\mathrm{CO}_{2}$ mole fraction (Ci) in Rosa leaves fed with ABA by using chlorophyll fluorescence imaging. Significance of Ci estimated from leaf gas exchange. Plant Physiol. 116, 947-958. doi: $10.1104 /$ pp.116.3.947

Nahar, K., Hasanuzzaman, M., Alam, M. M., and Fujita, M. (2015). Exogenous glutathione confers high temperature stress tolerance in mung bean (Vigna radiata L.) by modulating antioxidant defense and methylglyoxal detoxification system. Environ. Exp. Bot. 112, 44-54. doi: 10.1016/j.envexpbot.2014. 12.001

Qureshi, M. I., Qadir, S., and Zolla, L. (2007). Proteomics-based dissection of stress-responsive pathways in plants. J. Plant Physiol. 164, 1239-1260. doi: 10.1016/j.jplph.2007.01.013

Selote, D. S., and Khanna-Chopra, R. (2006). Drought acclimation confers oxidative stress tolerance by inducing co-ordinated antioxidant defence at cellular and subcellular level in leaves of heat seedlings. Physiol. Plant 127, 494-506. doi: 10.1111/j.1399-3054.2006.00678.x

Shehab, G. G., Ahmed, O. K., and El-Beltagi, H. S. (2010). Effects of various chemical agents for alleviation of drought stress in rice plants (Oryza sativa L.). Not. Bot. Hort. Agrobot. Cluj-Napoca 38, 139-148.

Son, J. A., Narayanankutty, D. P., and Roh, K. S. (2014). Influence of exogenous application of glutathione on rubisco and rubisco activase in heavy metal-stressed tobacco plant grown in vitro. Saudi J. Biol. Sci. 21, 89-97. doi: 10.1016/j.sjbs.2013.06.002

Sreenivasulu, N., Grimm, B., Wobus, U., and Weschke, W. (2000). Differential response of antioxidant compounds to salinity stress in salt-tolerant and salt sensitive seedlings of foxtail millet (Setaria italica). Physiol. Plant 109, 435-442. doi: 10.1034/j.1399-3054.2000.100410.x 
Sundaravalli, V., Paliwal, K., and Ruckmani, A. (2005). Effect of water stress on photosynthesis, protein content and nitrate reductases activity of Albizzia seedlings. J. Plant Biol. 32, 13-17.

Wang, R., Liu, S., Zhou, F., Ding, C., and Hua, C. (2014). Exogenous ascorbic acid and glutathione alleviate oxidative stress induced by salt stress in the chloroplasts of Oryza sativa L. Z. Naturforsch. 69c, 226-236. doi: 10.5560/ZNC. 2013-0117

Zlatev, Z. S., Lidon, F. C., Ramalho, J. C., and Yordanov, I. T. (2006). Comparison of resistance to drought of three bean cultivars. Biol. Plant 50, 389-394. doi: 10.1007/s10535-006-0054-9

Conflict of Interest Statement: The authors declare that the research was conducted in the absence of any commercial or financial relationships that could be construed as a potential conflict of interest.
Received: 11 December 2014; accepted: 17 December 2014; published online: 08 January 2015.

Citation: Anjum NA, Umar S, Aref IM and Iqbal M (2015) Managing the pools of cellular redox buffers and the control of oxidative stress during the ontogeny of droughtexposed mungbean (Vigna radiata L.) —role of sulfur nutrition. Front. Environ. Sci. 2:66. doi: $10.3389 /$ fenvs.2014.00066

This article was submitted to Environmental Toxicology, a section of the journal Frontiers in Environmental Science.

Copyright (C) 2015 Anjum, Umar, Aref and Iqbal. This is an open-access article distributed under the terms of the Creative Commons Attribution License (CC BY). The use, distribution or reproduction in other forums is permitted, provided the original author(s) or licensor are credited and that the original publication in this journal is cited, in accordance with accepted academic practice. No use, distribution or reproduction is permitted which does not comply with these terms. 